\title{
Antioxidant Activities of Centella asiatica Extract-loaded Bovine Serum Albumin Nanoparticles in Simulated Gastrointestinal System Study
}

\author{
Kittiya Kesornbuakao ${ }^{1}$, Patteera Chanapongpisan ${ }^{1}$, Malinee Sriariyanun ${ }^{2}$, Ir. Lindayani ${ }^{3}$, and Patchanee Yasurin ${ }^{1, *}$ \\ ${ }^{1}$ Food Biotechnology Program, Faculty of Biotechnology, Assumption University, Bangkok, Thailand \\ ${ }^{2}$ Department of Mechanical and Process Engineering, The Sirindhorn International Thai-German Graduate School of Engineering \\ (TGGS), King Mongkut's University of Technology North Bangkok, Bangkok, Thailand \\ ${ }^{3}$ Food Technology Program, Soegijapranata Catholic University (SCU), Semarang, Indonesia
}

\begin{abstract}
Bioavailability of active compounds extracted from herbs is generally limited to be adsorbed or expressed to target organisms due to several physical and chemical factors. Nanoparticle encapsulation techniques was developed to carry bioactive macromolecules of Centella asiatica (Buabok) in the form of C. asiatica Extract-loaded Bovine Serum Albumin Nanoparticles (CBNPs) to improve bioavailability. In this study, the antioxidant activities of CBNPs and C. asiatica crude extract were evaluated by using DPPH radical scavenging assay in the simulated gastrointestinal system, including mastication, stomach, duodenum, and ileum conditions to provide the environment which similar to in vivo system in terms of chemical and physical parameters. CBNPs were prepared by mixing of $C$. asiatica crude extract and BSA at different ratio of 1:2, 1:3, and 1:4. The results showed that the highest antioxidant activity of CBNP was observed when the ratio of crude extract and BSA at 1:2 was used at $\mathrm{pH} 2.0$ or in the simulated stomach condition. The denaturation or unfolding of BSA in the simulated stomach occurred when $\mathrm{pH}$ was low could lead to the release of active compounds at certain area in gastrointestinal system.
\end{abstract}

\section{Introduction}

Centella asiatica, so called Buabok in Thai, is one of top five Thailand Champion Herbal Products selected by the Department for Development of Thai Transitional and Alternative Medicine, Ministry of Public Health due to their potential uses in high value products of pharmaceutical, cosmetic, human health sectors $[1,2]$. C. asiatica is generally found in the tropical and subtropical areas, mostly in South East Asia region, including Thailand and in some areas of Western continent of the earth. C. asiatica has been included to be the medicinal herbal plants in conventional and ancient treatments. Additionally, it has been consumed in daily human meals in Asia. C. asiatica has been demonstrated in laboratories and clinical tests for its biological activities including antimicrobial activity, antioxidant activity, antiinflammatory activity, wound healing activity and, anticancer activity [3].

C. asiatica has been reviewed in several studies to consist of various chemical compositions with biological benefits i.e. to symptom treatment, to wound and injury treatment and to mentality treatments [3-4], C. asiatica is abundant in phenolic and flavonoid compounds, which are the key chemicals with antioxidant properties to protect human health against attack of free radical compounds [5-7]. Terpenes compounds including monoterpenes, sesquiterpene, and triterpenoids, especially asiaticoside and asiatica acid are the major bioactive compounds existing in $C$. asiatica extracts. However, the molecular size and chemical properties of these bioactive compounds result in less than $50 \%$ of these compounds are adsorbed by human consumption or treatment [8-11].

Previously, the bioactive absorption and drug delivery efficiency of crude extract of $C$. asiatica under in vitro condition were demonstrate with high potential for further uses [12], however in vivo system has not yet been demonstrated. Several techniques such as capsules, solid dispersion, dry emulsion, pellets and tablets, microsphere, nanoparticles, suppositories, and implants are applied to improve the efficiency of drugs [13]. Formulations of bioactive compounds with carriers molecules, such as polylactic-co-glycolic acid (PLGA), Bovine Serum Albumin (BSA), and Gelatin, in nanomolecular scale are conducted to improve bioavailability and biological activities including antibacterials, antioxidants in in vitro system [14-18].

In this study, crude extracts of $C$. asiatica was formulated with BSA to form $C$. asiatica Extract-loaded Bovine Serum Albumin Nanoparticles (CBNPs) by using the desolvation method, which increases dispersibility, biocompatibility and solubility of active compounds [19]. The antioxidant activities of CBNPs was monitored in the the simulated gastrointestinal system, including mastication, stomach, duodenum, and ileum conditions to provide the environment in terms of chemical and

\footnotetext{
* Corresponding author: patchaneeYsr@au.edu
} 
physical parameters, which similar to in vivo system of human digestive system.

\section{Materials and methods}

\subsection{Extraction of C. asiatica active compounds}

Fresh $C$. asiatica was purchased from local markets in Bangkok, Thailand. In this study, only the aerial part of $C$. asiatica was used. The fresh plant materials were washed with tap water to remove the contaminants and dusts. The samples were cut into small pieces and air dried in oven (Memmert UM500) at $45^{\circ} \mathrm{C}$. The dried samples were finely ground into powder using kitchen homogenizer. The powder was kept at $4{ }^{\circ} \mathrm{C}$ before used [11].

C. asiatica powder was mixed with $95 \%$ ethanol as the selected extraction solvent in this study at $10 \% \mathrm{w} / \mathrm{v}$. The mixtures were macerated at room temperature using magnetic stirrer set at $120 \mathrm{rpm}$, for 48 hours, and then were filtered using Whatman filter paper no. 4 . The $C$. asiatica crude ethanolic extracts was evaporated at $45^{\circ} \mathrm{C}$ by using rotary evaporators (BUCHI Rotavapor R-205). The crude extract was stored at $-20^{\circ} \mathrm{C}$ prior to use in preparation of CGNP $[11,20]$.

\subsection{Preparation of $C$. asiatica extract-loaded BSA nanoparticles}

CBNP was prepared by using the desolvation method based on the protocol described in previous study with minor modification [21]. The $100 \mathrm{mg}$ of BSA powder were resuspended in $1 \mathrm{~mL}$ of $10 \mathrm{mM}$ sodium chloride solution. Then, $8.0 \mathrm{~mL}$ of ethanol was added dropwise into the BSA solution under magnetic stirring (400 rpm) at room temperature. Subsequently, the BSA nanoparticles were cross-linked and polymerized with addition of $0.2 \%$ glutaraldehyde (GA). Then, C. asiatica crude ethanolic extract was added into the BSA nanoparticles solution at different ratio of $C$. asiatica to BSA at ratio of $1: 2,1: 3$, and $1: 4$ and the mixtures were continuous stirred for $24 \mathrm{~h}$. The CBNPs were harvested from mixtures by using centrifugation and they were washed again with distilled water. The CBNPs particles were resuspended and disperse in $2 \%$ mannitol, then freeze-dried. The dried nanopowder were kept at $4{ }^{\circ} \mathrm{C}$ before used.

\subsection{Set up of in vitro simulated gastrointestinal system}

The experiment to evaluate the biological activity of CBNPs particles was conducted in the simulated digestive system as developed in Verruck, et al., 2015 [21]. The simulated gastrointestinal system was divided to 4 main parts, including mouth, oesophagus-stomach, duodenum and ileum. The physical condition as shaking speed and time, the chemical conditions as enzymes and $\mathrm{pH}$ were controlled as in human digestive tracts and temperature was set at $37^{\circ} \mathrm{C}$ as shown in Table 1 .
In mouth phase or mastication, the $1 \mathrm{mg} / \mathrm{mL}$ of CBNPs and $C$. asiatica crude ethanolic extract were mixed in $1 \mathrm{M} \mathrm{NaHCO}_{3}$ buffer, pH 6.9 then $100 \mathrm{U} / \mathrm{mL}$ of $\alpha$-amylase and $1 \mathrm{mM} \mathrm{CaCl} 2$ as saliva solution were added at the rate of $0.6 \mathrm{~mL} / \mathrm{min}$ for $2 \mathrm{~min}$, and stirred at $200 \mathrm{rpm}$ [22]. Then, as transition to oesophagus-stomach phase, the sample was continuously added with $1 \mathrm{M} \mathrm{HCl}$ solution until $\mathrm{pH} 2.0$, and $0.05 \mathrm{~mL} / \mathrm{g}$-sample of pepsin solution was added and the sample was stirred at $130 \mathrm{rpm}$ for $90 \mathrm{~min}$. As in duodenum phase, the tested sample was added with $0.25 \mathrm{~mL} / \mathrm{g}$-sample of pancreatin-bovine bile salts solution, and the $\mathrm{pH}$ was adjusted to 5.0 by addition of $1 \mathrm{M} \mathrm{NaHCO}_{3}$. Sample was stirred at $45 \mathrm{rpm}$ for $20 \mathrm{~min}$ as the duodenum section. Finally, as in ileum phase, $\mathrm{pH}$ of sample was adjusted to 6.5 by addition of $1 \mathrm{M} \mathrm{NaHCO}_{3}$ and the sample was stirred at $45 \mathrm{rpm}$ for $90 \mathrm{~min}$. The tested samples collected from each simulated digestive tract phase were harvested by centrifugation at 7,000 rpm for $10 \mathrm{~min}$. The pellet was collected for further analysis.

Table 1. The experimental condition testing of CBNPs in simulated gastrointestinal system [21].

\begin{tabular}{|c|c|c|c|c|}
\hline \multirow[b]{2}{*}{ Phase } & \multicolumn{2}{|c|}{$\begin{array}{l}\text { Chemical } \\
\text { parameters }\end{array}$} & \multicolumn{2}{|c|}{$\begin{array}{c}\text { Physical } \\
\text { parameters }\end{array}$} \\
\hline & Composition & $\mathrm{pH}$ & $\begin{array}{l}\text { Shaking } \\
\text { speed } \\
\text { (rpm) }\end{array}$ & $\begin{array}{c}\text { Retention } \\
\text { Time } \\
\text { (min) }\end{array}$ \\
\hline Mouth & $\begin{array}{l}\alpha \text {-amylase, } \\
\mathrm{CaCl}_{2}\end{array}$ & 6.9 & 200 & 2 \\
\hline $\begin{array}{l}\text { Oesophagus } \\
\text {-Stomach }\end{array}$ & $\begin{array}{l}\text { Pepsin } \\
\mathrm{HCl}\end{array}$ & $\begin{array}{l}\text { Starting at } \\
\mathrm{pH} \quad 5.5 \\
\text { and } \\
\text { gradually } \\
\text { drop to } \\
\mathrm{pH} 2.0\end{array}$ & 130 & 90 \\
\hline Duodenum & $\begin{array}{l}\text { Pancreatin, } \\
\text { Bile salts, } \\
\mathrm{NaHCO}_{3}\end{array}$ & 5.0 & 45 & 20 \\
\hline Ileum & $\mathrm{NaHCO}_{3}$ & 6.5 & 45 & 90 \\
\hline
\end{tabular}

\subsection{DPPH antioxidant assay}

$\alpha, \quad \alpha$-diphenyl- $\beta$-picrylhydrazyl (DPPH) free radical scavenging method [23-27] was selected as the test assay for antioxidation activity of CBNPs and $C$. asiatica crude ethanolic extract in this study with minor modification. The $100 \mu \mathrm{L}$ of tested samples, crude extract or CBNPs, and $3.9 \mathrm{~mL}$ of $50 \mu \mathrm{m}$ methanol DPPH solution is shaken thoroughly and kept in the dark room for 30 minutes. The optical density at $517 \mathrm{~nm}$ of tested mixtures was measured by UV-vis spectrophotometer with three replicates. The results are expressed as percentage of DPPH radical scavenging to original activity before testing in simulated gastrointestinal system.

All experiments were conducted in three replications and statistical analysis was accomplished using ANOVA with Duncan's multiple range tests $(p<0.05)$ by SAS software version 9.4. 


\section{Result and Discussion}

C. asiatica has valuables properties, such as antimicrobial, antioxidant, wound healing activity, anti-inflammatory activity, and anticancer activity, which make it has high potential to be used as the active ingredient in high value industry products. In this study, $C$. asiatica crude ethanolic extract and CBNP nanoparticles were prepared from fresh $C$. asiatica plants (Fig. 1). The freeze dried CBNP powder has light green color compared to original crude ethanolic extract. In our previous works, the $C$. asiatica crude ethanolic extract were demonstrated to be well active in inhibition of the several pathogenic bacteria [3, $11,17,18]$. However, nanoencapsulation of crude extract with gelatin nanoparticle were demonstrated in in vitro simulated gastrointestinal system to have less antibacterial and antioxidant activities compared to the crude extract [18].
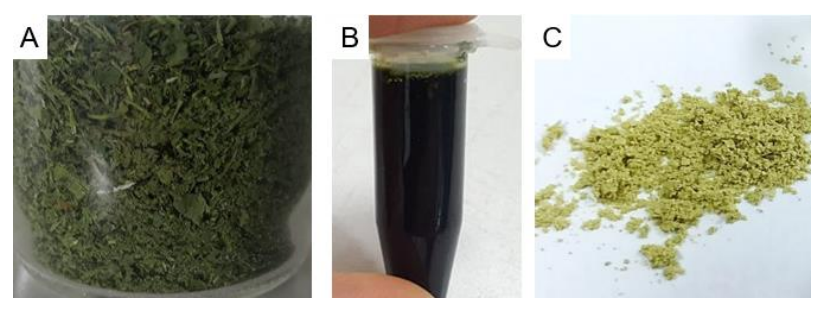

Fig. 1. Preparation of $C$. asiatica crude ethanolic extract and CBNP nanoparticles. (A) Ground $C$. asiatica plants, (B) $C$. asiatica crude ethanolic extract and (C) CBNP nanoparticles.

Although the crude extracts of herbs, including C. asiatica have been demonstrated in vitro previously to have high efficient and potential in various biological activities [11]. However, these active compounds are expected to be maintain their activities when using in vivo condition. However, the experiment set up for in vivo testing is normally more complex to control the condition to obtain the consistent results, also the ethic regulation is necessary to be followed. Therefore, the experiment using simulated gastrointestinal system was set up according to mastication, stomach, duodenum, and ileum conditions to be similar to human gastrointestinal tract. Using nanoencapsulation technique to modify hydrophilicity and drug release capacity of $C$. asiatica crude extract was expected to promote the stability of bioactivity and bioavailability in in vitro digestive system [28, 29].

In order to study an effectiveness of CBNPs on maintaining the antioxidant activity when they were challenged with conditions in simulated gastrointestinal system, CBNPs and $C$. asiatica crude extract were treated with the enzymes, chemicals, and physical conditions, including temperature, $\mathrm{pH}$ and retention time were adjusted to mimic gastrointestinal tract condition in human. Biological active compounds are commonly found in herbal products, i.e. C. asiatica in large quantity [30]. These active compounds help to inactivate free radical generating either from food consumption or stress [5]. Scavenging method is widely chosen to measure antioxidant activity in which free radical compounds are caught by active compound [6]. C. asiatica contains various types of active chemicals which can function as antioxidant activity, especially phenolic compounds and triterpenoids. The different mechanisms of antioxidants could be due to inactivation of free radicals, reactive oxygen species scavenging, and chain-breaking activity [31-33]. In this study, DPPH radical scavenging assay was used for evaluating antioxidant activity of CBNPs and $C$. asiatica crude extract collected from simulated gastrointestinal system.

Firstly, CBNPs and C. asiatica crude extract were tested in mouth phase by treating the samples with $\alpha$-amylase and calcium chloride at $\mathrm{pH} 6.9$, both CBNPs and $C$. asiatica crude extract showed no significantly different in antioxidant activity $(p<0.05)$ (Fig. 2). In Oesophagus-Stomach phase, Pepsin and hydrochloric acid were included in the system and $\mathrm{pH}$ value was gradually dropped from $\mathrm{pH} 5.5$ to $\mathrm{pH} 2.0$. Antioxidant activities of all tested CBNPs started to drastically increase, while the activity of $C$. asiatica crude extract was slowly increase. Antioxidant activity of all tested CBNPs showed significantly higher than C. asiatica crude extract at this phase and the highest antioxidant activity of CBNP formulations was the ratio between $C$. asiatica to BSA at ratio of 1:2 (Fig. 2). However, it could be observed that different formulations of CBNPs based on the amounts of BSA were not really have big impacts on maintaining antioxidation activities.

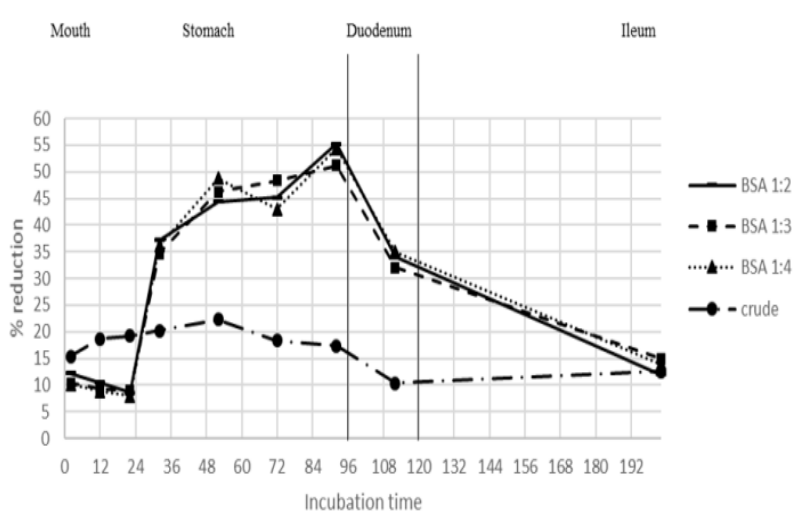

Fig. 2. Oxidation activities throughout incubation time in minute of CBNPs and $C$. asiatica crude extract in simulated gastrointestinal system measured by using DPPH radical scavenging assay. Different formulations of CBNPs prepared from mixing between $C$. asiatica to BSA at ratio of 1:2, 1:3 and 1:4 were tested.

For duodenum and ileum phase, pancreatic bile salts and sodium bicarbonate were added into the system to create small intestine conditions and $\mathrm{pH}$ was controlled to be at $\mathrm{pH}$ 5.0-6.5. Antioxidant activities of all CBNP formula decreased when they were in simulated environment of duodenum phase at $\mathrm{pH}$ 5.0. However, antioxidant activities of CBNPs and crude extract showed no significantly different when they were challenged in the ileum condition.

The fluctuations of antioxidant activities of CBNPs that made them different from crude extract could be explained by the changing in 3D molecular structure and hydrogen bonding of BSA and active compounds during cross linking reactions. These chemical bonds trapped the biological-active chemicals inside the nanoparticles. 
When the chemical and physical conditions in simulated gastrointestinal system were set to mimic the condition in vivo, those chemical crosslinking bonds in nanoparticles were modified accordingly and release the active compounds out. It clearly showed that CBNPs had the highest antioxidant activities in simulated stomach condition at $\mathrm{pH}$ 2.0. Their activities rapidly dropped in duodenum section at $\mathrm{pH} 5.0$ because BSA naturally unfolded or denatured when the $\mathrm{pH}$ lower than 4.0 and it can be renatured and stable at $\mathrm{pH} 4.0-9.0$ [34]. Moreover, crosslinking bonds also helped to stabilize the protein nanoparticles and to reduce enzymatic degradation and to promote drug release from the nanoparticles [35].

\section{Conclusion}

Based on the fact that drug release efficiency depends on various factors including the carrier of active compounds, which affects the bioavailability and controls transportation and the level of activities in target cells. This study, the preparations of CBNPs from the mixtures of $C$. asiatica crude ethanolic extract and nanomolecular carrier, BSA were conducted. The antioxidant activities of CBNPs and crude extract were monitored and compared in in vitro simulated gastrointestinal system, which mimicking the in vivo condition in human digestive tract. The nanoencapsulation with BSA showed the maintaining in the level of antioxidant activities compared to crude extract, which are clearly different from results of nanocapsulation with gelatin in our previous study. CBNPs could help to regulate the release of active compounds at certain phase in gastrointestinal system and improved drug release from the nanoparticles at early gastrointestinal tract. These results suggested the importance of carrier selection for development of drugs from herb products.

Authors would like to thank you King Mongkut's University of Technology North Bangkok for financial support of this project (Grant number: KMUTNB-62-KNOW-01).

\section{References}

1. B. Wongpanit, C. Chotikamas, S. Roddecha, P. Tantayotai, M. Sriariyanun, (4th International Conference on Chemical Materials and Process (ICCMP2018)). MATEC Web of Conferences 187, 01002 (2018).

2. S. Chotikamas, K. Cheenkachorn, B. Wongpanit, P. Tantayotai, M. Sriariyanun, (4th International Conference on Chemical Materials and Process (ICCMP2018)). MATEC Web of Conferences 187, 01001 (2018).

3. P. Yasurin, M. Sriariyanun, T. Phusantisampan, KMUTNB Int J Appl Sci Technol 9, 1 (2016).

4. A. J. Das, J Biol Act Prod Nat. 1,4 (2011)

5. D. de Beer, E. Jouber, W.C.A. Gelderblom, M. Manley, South Afri J Enol Viti. 23 (2002)

6. D. Huang, B. Ou, R.L. Prior, J Agric Food Chem. 53 (2005)
7. W. Rodiahwati, A. Nopitasari, I.K. Saleh, Appl Sci Eng Prog. 12, 1. (2018).

8. N. Pitinidhipat, P. Yasurin, AU J T. 15 (2012)

9. C. V. Utami, N. Pitinidhipat, P. Yasurin, KMITL Sci Tech J. 12 (2012)

10. B. Mamtha, K. Kavitha, K.K. Srinivasan, P.G. Shivananda, Indian J Pharmacol. 36 (2004)

11. S. Rattanakom, P. Yasurin, Orient J Chem. 34 (2015)

12. W. Kriengsinyos, C. Chitchumroonchokchai, P. Siriprapa, FASEB J. 20 (2006)

13. P. Khadka, Asia J Pharm Sci., 9 (2014)

14. X. Xie, Q. Tao, Y. Zou, F. Zhang, M. Guo, Y. Wang, H. Wang, Q. Zhou, S. Yu, J Agric Food Chem. 59 (2011)

15. M.S. Huang, K. Kitsubthawee, J. Phetsom, P. Chanapongpisa, I.r. Lindayani, P. Yasurin, Appl Sci Eng Prog. 13, 1 (2020)

16. Y. Zhan, Y. Min, Z. Zhang, G. Hong, Q. Xiong, Nanoscale Res Lett. 9 (2014)

17. K. Kesornbuakao, P. Yasurin, Orient J Chem. 32 (2016)

18. K. Yongsirasawad, P. Sanvarinda, N. Sornritchinchai, P. Yasurin, KMUTNB Int J Appl Sci Technol. 10, 3 (2017)

19. P. Singh, H. Singh, C. Verónica, S. Ahn, Y. Ju Kim, D.C. Yang, RSC Adv. 25 (2017)

20. S. Chaichoowong, J.B. Bol, P. Bol, T. Gamse, M. Sriariyanun, Orient J Chem. 33, 1 (2017)

21. S. Verruck, Food Sci Technol. 63 (2015)

22. S. Y. Choi, Food Control 18 (2007)

23. W. Brand-Williams, M. E. Cuvelier, C. Berset, Lebensm. Wiss. Technol. 28 (1995)

24. N. Chairerk, P. Pongyeela, J. Chungsiriporn, N. Rakmak, Appl Sci Eng Prog. Online published. (2020)

25. K. Jangja, N. Saewan, W. Vichit, KMUTNB Int J Appl Sci Technol. 11, 4 (2018)

26. V. Seechamnanturakit, T.T. Karrila, C. Sontimuang, A. Sukhoom, KMUTNB Int J Appl Sci Technol. 11, 1 (2018)

27. N.T.T. Thao, C. Niwat, KMUTNB Int J Appl Sci Technol. 11, 1 (2018)

28. V. Ghosh, Colloids Surf. B Biointerfaces. 105 (2013)

29. R. Rajendran, Carbohydr Polym. 91 (2013)

30. N.V. Yanishlieva, E. Marinova, J. Pokorny, Eur J Lipid Sci Technol. 108 (2006)

31. T. Hatano, Chem Pharm Bull. 37 (1989)

32. J. Laranjinha, O. Vieira, V. Madeira, L. Almeida, Arch Biochem Biophys. 323 (1995)

33. S.A.V. Acker, Biochem Pharmacol. 56 (1998)

34. F. Kratz, J. Control Release 132 (2008)

35. L. Warangkana, W. Liying, C. Yi Charlie, R.Yon, Biomed Res Int. (2014). 